\title{
Lasting Resolution of Diabetic Macular Edema and Stable Improvement of Visual Acuity after Treatment with Pars Plana Vitrectomy
}

\author{
Claus E. Jahn ${ }^{a}$ Dörte C. Schöpfer ${ }^{a}$ Thomas Heinzle ${ }^{a}$ Jürgen Boller ${ }^{b}$ \\ Patricia V. Schwachac Silvia Sander ${ }^{d}$ Martina Kron ${ }^{d}$ \\ ${ }^{a}$ Augenpraxisklinik Dr. Jahn, Pfeiffer und Kollegen, Kempten, b Praxis Dr. Boller, Krumbach, 'Augenabteilung, \\ Bundeswehrkrankenhaus, und ${ }^{d}$ Institut für Biometrie, Medizinische Fakultät der Universität Ulm, Ulm, Deutschland
}

\section{Background}

We refer to our earlier publication in this journal [1] in which we - in agreement with the results obtained by many other investigators - reported a short-term beneficial effect of pars plana vitrectomy (PPV) on the morphological and functional characteristics of eyes with diabetic macular edema. Since the duration of a beneficial effect of PPV on diabetic macular edema is not exactly known at present, we would like to add our long-term observations made in this cohort.

\section{Patients and Methods}

During the course of the study, 8 of initially 21 patients (30 consecutive eyes) died and 3 patients were unavailable for examination, resulting in 10 patients available for the long-term follow-up. Basic clinical evaluations, including fluorescein angiography and optical coherence tomography in selected cases, were carried out.
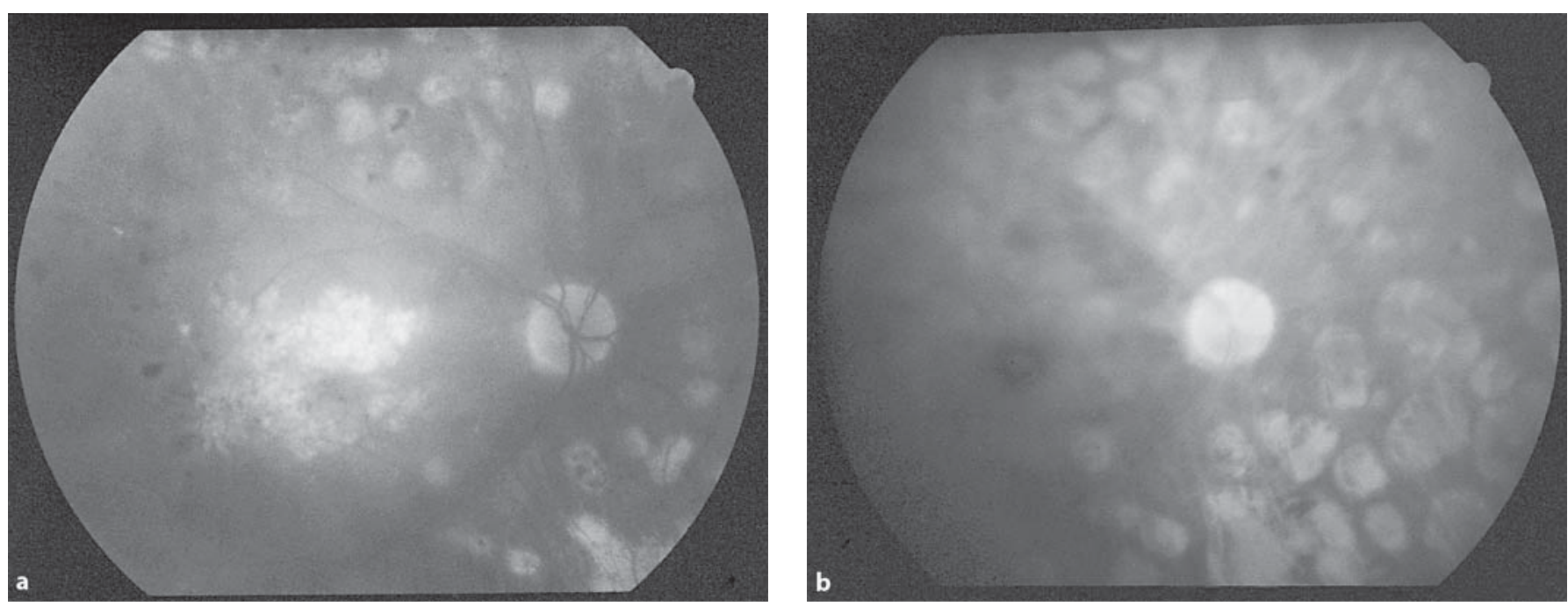

Fig. 1. a, b Decrease in leakage of fluorescein 64 months after PPV in the eye of a patient who was 60 years old when he underwent PPV.

\section{KARGER}

Fax +41613061234 E-Mail karger@karger.ch www.karger.com
Dr. Claus E. Jahn

Augenpraxisklinik Dr. Jahn, Pfeiffer und Kollegen

Bodmanstrasse 8

DE-87435 Kempten (Germany)

Tel. +49 831 14041, Fax +49831 27294, E-Mail praxisdr.jahn@t-online.de 


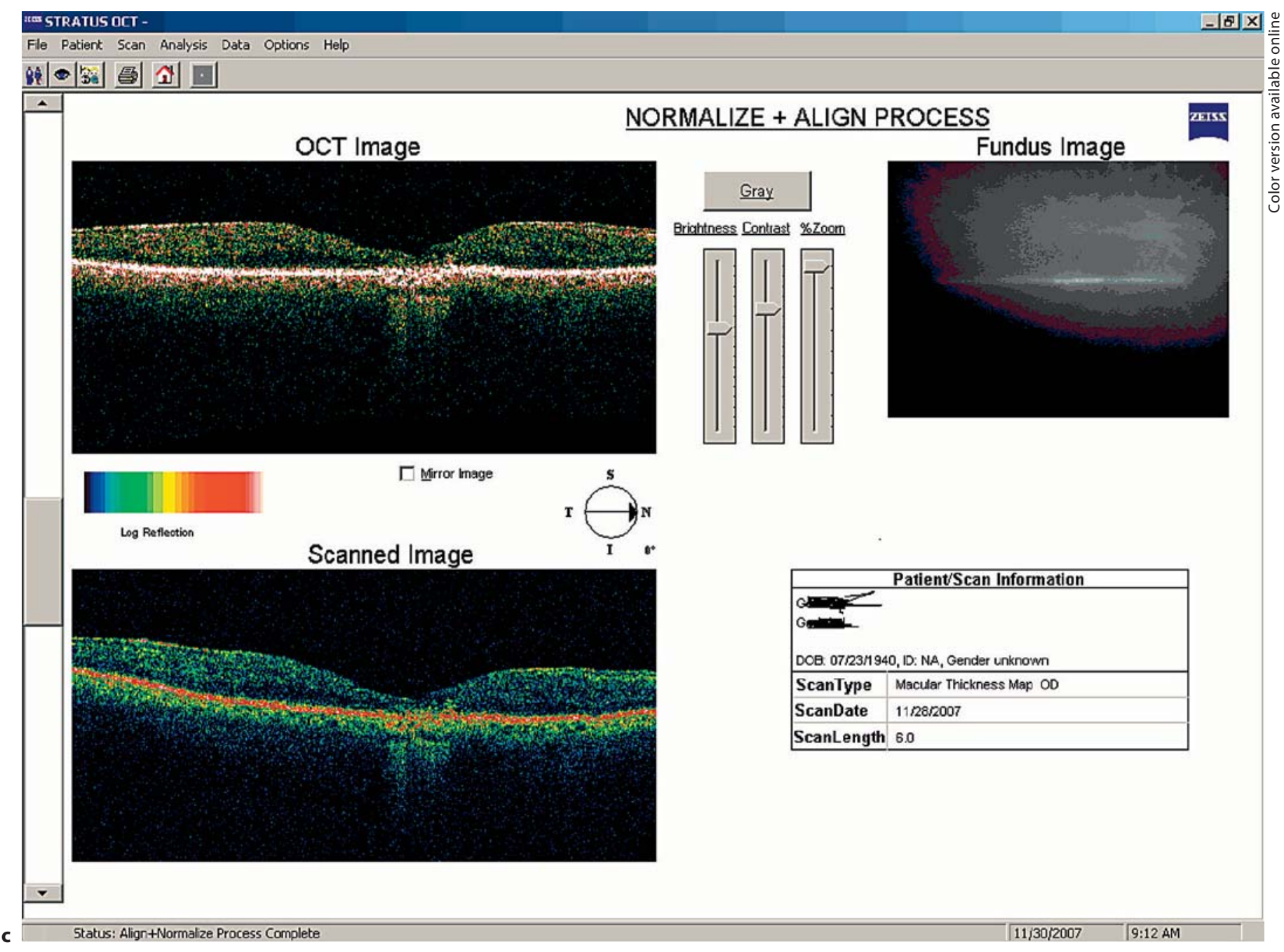

Fig. 1. c The optical coherence tomography (OCT) image of that eye was taken 82 months after PPV. Visual acuity increased from 0.03 to 0.2 .

\section{Results}

The macula was flattened or attached in $17 / 22(77 \%)$ eyes at 12 months, in $12 / 14$ (86\%) eyes at 48 months and in $8 / 10(80 \%)$ eyes at $\geq 60$ months after PPV.

Compared to the time of surgery, leakage during fluorescein angiography was decreased or had disappeared in 11/14 (79\%) eyes which we examined 30-60 months after PPV (fig. 1a, b). Optical coherence tomography in 5/5 eyes tested 60 82 months after PPV showed absence of macular edema (fig. 1c).
Mean visual acuity increased markedly from $0.13 \pm 0.09$ before PPV to $0.30 \pm$ 0.21 during the 12 months after PPV and was still $0.25 \pm 0.23$ after an interval of 60 months following PPV.

\section{Discussion}

We saw that as a result of PPV all outcome measures examined remained essentially stable at an improved level during the extended period of observation. We conclude that the positive effect of
PPV on diabetic macular edema lasts for the long run, which is important since half of the patients in this cohort needed treatment that is efficacious for more than 5 years.

\section{Reference}

1 Jahn CE, Töpfner von Schütz K, Richter J, Boller J, Kron M: Improvement of visual acuity in eyes with diabetic macular edema after treatment with pars plana vitrectomy. Ophthalmologica 2004;218:378-384. 